\title{
STUDIES ON EFFECTS OF SHORT COIR FIBER REINFORCEMENT ON FLEXURAL PRPPERTIES OF POLYMER MATRIX
}

\author{
P.A.Udaykumar ${ }^{1}$, Rajanna $\mathrm{S}^{\mathbf{2}}$, Ramalingaiah $^{3}$ \\ ${ }^{1}$ GSS Institute of Technology, Bangalore, Karnataka, India \\ ${ }^{2}$ PES College of Engineering, Mandya, Karnataka, India \\ ${ }^{3}$ Govt. Engineering College, Kushalanagar, Karnataka, India
}

\begin{abstract}
For environmental concern on synthetic fibers (such as glass, carbon, ceramics etc) natural fibers such as sisal, flax, hemp, jute, kenaf, coir etc., are widely used. In this research work, short coir fibers reinforced polymer composite have been developed by hand layup techniques with varying fiber percentages $(5 \%, 10 \%, 15 \%, 20 \%, 25 \%$ by weight). The developed coir fiber reinforced composites were then tested for their FLEXTURAL properties. The result shows that a flexural property increases with increases in fiber percentage; however after a certain fiber weight percentage the properties are decreased. From the data of tested results conclude that $20 \%$ of coir reinforcement at 4 mm thickness of polymer composite exhibited higher percentage of elongation. The coir fiber in the present study could be used as an effective reinforcement for making composites, which have an added advantage of being light weight
\end{abstract}

Keywords: Polypropylene, Composites, Flexural, Coir and Reinforcement.

\section{INTRODUCTION}

Natural fibers are lignocellulosic in nature and the most abundant renewable biomaterial of photosynthesis on earth . Underutilized natural fiber residues are readily available rich resources of lignocellulosic materials. Since last decade, there is considerable interest worldwide in the potential of substituting natural fibers agro fibers) for either wood or manmade fiber in composite materials. Composites consisting lignocellulosic fibers and synthetic thermoplastics have received substantial attention in scientific literatures well as in industry, primarily due to improvements in process technology and economic factor. Natural fibers such as jute, flux, hemp, etc. can be alternately used to reduce the cost of the composites. The prominent advantages of natural fibers include acceptable specific strength properties, low cost; low density and high toughness The mechanical properties of some natural fibers such as jute, sisal, and flaw fibers were compares to glass fibers and it was observed that specific module of these fibers are comparable to or better than those of glass fibers

Different composites based on polypropylene and reinforced with flax and glass have been made and their mechanical properties are measured together with the distribution of the fiber diameter composites of polypropylene and four different types of natural fibers including wood flour, ricehulls, kenaf fibers, and news print were prepared at 25 and $50 \%$ fiber contents and their dynamic mechanical properties were studied and compared with the pure plastic. The mechanical properties of bamboo fiber-reinforced polypropylene composites are compared with commercially available wood pulp board and it is reported that bamboo fiber composites are lighter, water resistant, and cheaper and has more tensile strength than the wood pulp composites. A systematic study of the mechanical properties of the composites as a function of fiber loading, and fiber treatment time has been made for sisal polypropylene composites.

The main objective of this paper was coir fiber is identified as potential reinforcement for making composites. Coir fiber reinforced vinyl ester matrix composites have been developed by hand layup technique with varying percentage of weight by $(5 \%, 10 \%, 15 \%, 20 \%, 25 \%)$ the developed composites were then tested for flexural property.

\section{MATERIAL AND METHODS}

\subsection{Materials}

The composites were produced using coir fibers and vinyl ester resin. The ling coir fibers were chopped with help of hand scissors and cleaned with mesh, all dirt's are removed from the chopped coir fiber. The chopped coir fibers were then cleaned with fresh water and then dried.

\subsection{Composite Fabrication}

The mould was fabricated with $300 \mathrm{~mm}^{*} 300 \mathrm{~mm} * 6 \mathrm{~mm}$ dimension as shown in the Fig 1 . The mould was cleaned with wax as a releasing agent. The mixture of coir and vinyl ester 
prepared according to the weight fraction and poured in to the mould. Promoter and hardener and catalyst was added proportionally as shown in the Fig2. Composite of different weight fraction of coir vinyl ester composites and different thickness specimens were prepared for conducting flexural test.

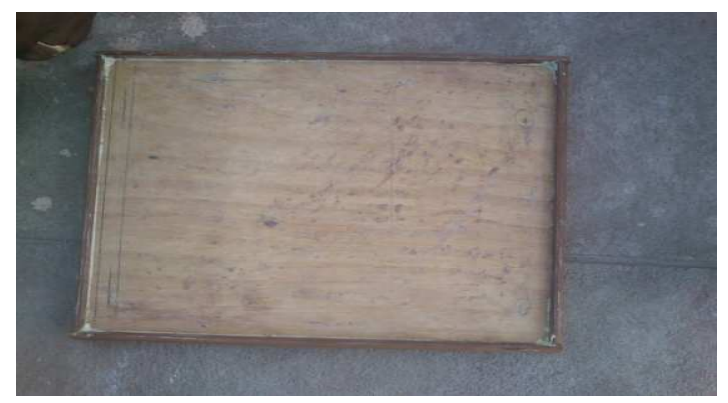

Fig- 1: Open mould

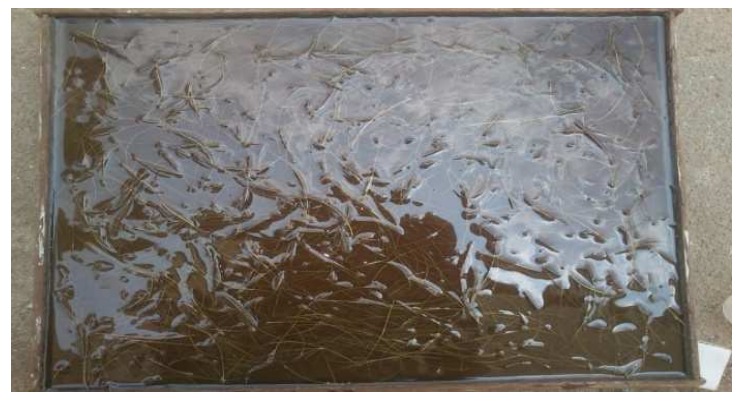

Fig-2: Preparation of laminates

\subsection{Specimen Preparation}

The prepared laminates were taken for cutting in band saw cutting machine. The specimens were prepared according to ASTM standards as shown in the Fig3. Flexural specimen code is D790 for composite materials. and the specimen dimensions are total length of specimen: $80 \mathrm{~mm}$, gauge length of specimen: $50 \mathrm{~mm}$ and total width of specimen: $10 \mathrm{~mm}$.

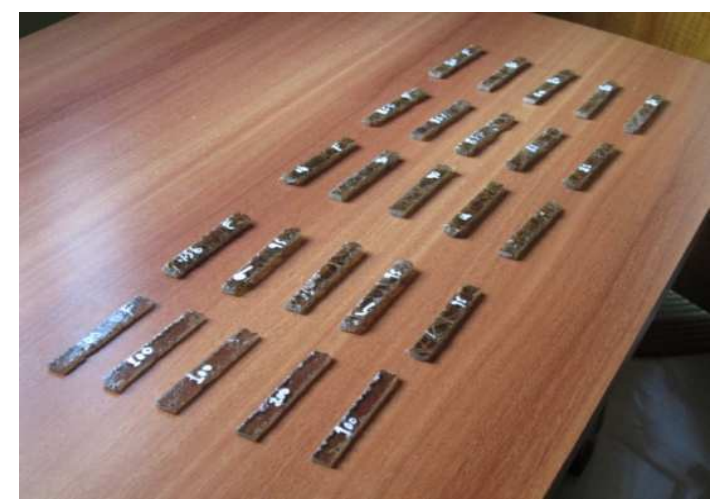

Fig- 3: Prepared Flexural specimens

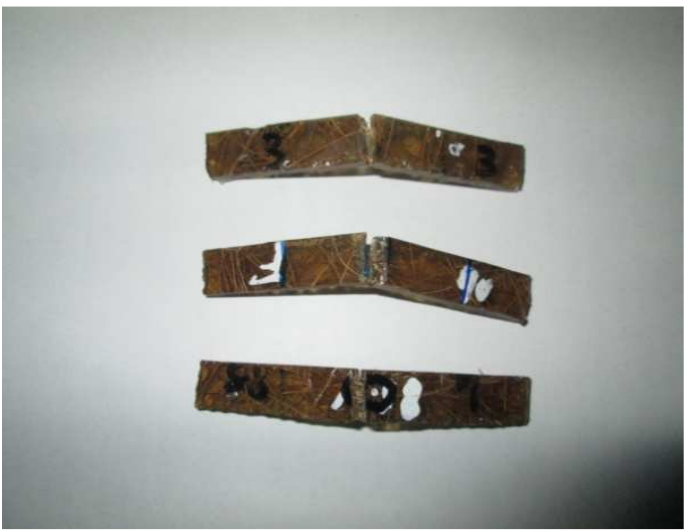

Fig-4: Failure specimen

\subsection{Flexural Test}

Flexural Test has been done for the prepared 25 specimens in the material testing center at composite technology park Bangalore(promoted by Karnataka housing board and RV TIFIC composites design center and supported by department of C \& I, RGRHC of Govt of Karnataka and DST, BMPTC and HUDCO OF GOVT of India) to determine the tensile property of the materials. This machine comes from LLYOD instruments, UK. This machine is linked to a remote computer and data analysis software. The maximum capacity is $50 \mathrm{kN}$ and hence it is designated as "LLYOD LR $50 \mathrm{~K}$ ". Using this testing machine and by deploying suitable jigs and fixtures. Flexural test pertaining to the evaluation of material properties can be determined very precisely. The transverse bending test is most frequently employed, in which a rod specimen having rectangular cross-section is bent until fracture using a three point flexural test technique. The flexural strength represents the highest stress experienced within the material at its moment of rupture. It is measured in terms of stress, here given the symbol $\sigma$. Most materials fail under tensile stress before they fail under compressive stress, so the maximum tensile stress value that can be sustained before the beam fails is its flexural strength and fail in flexural test as shown in the Fig4.

\section{RESULTS AND DISCUSSION}

The present experimental investigation percentage of coir reinforcement and thickness variables were considered for achievement of the objectives. Fiber reinforced polymer composites were prepared by hand layup techniques with varying fiber percentages $(5 \%, 10 \%, 15 \%, 20 \%, 25 \%$ by weight and also varying thickness of composites.. The developed coir fiber reinforced composites were then tested for their FLEXTURAL properties. Flexural test has been conducted for all samples of varying fiber percentage and thickness of the composite. The flexural test was indicated flexural strength and percentage of elongation. Flexural tested results were tabulated and presented in the tables from tables1 
to 5.each trial five samples were tested and tabulated average results in the table. The result shows that a flexural property increases with increases in fiber percentage up to20 percentage of coir reinforcement and then decreases. I.e. trend was increased still reaches $20 \%$ and then trend decline. The coir fiber in the present study could be used as an effective reinforcement for making composites, which have an added advantage of being light weight.

Table 1: Thickness V/S \% of elongation and Flexural strength of $5 \%$ reinforcement of coir

\begin{tabular}{|l|l|l|l|}
\hline $\begin{array}{l}\text { Percentage of } \\
\text { coir } \\
\text { reinforcemen } \\
\mathrm{t}\end{array}$ & $\begin{array}{l}\text { Thicknes } \\
\mathrm{s} \text { in } \mathrm{mm}\end{array}$ & $\begin{array}{l}\text { Percentag } \\
\mathrm{e} \quad \text { of } \\
\text { elongation }\end{array}$ & $\begin{array}{l}\text { Flexura } \\
\text { l } \\
\text { strength } \\
\text { in MPa }\end{array}$ \\
\hline \multirow{5}{*}{5} & 3 & 6 & 52 \\
\cline { 2 - 4 } & 3.5 & 6.7 & 54 \\
\cline { 2 - 4 } & 4 & 6.9 & 58 \\
\cline { 2 - 4 } & 4.5 & 6.1 & 57 \\
\cline { 2 - 4 } & 5 & 5.5 & 55 \\
\hline
\end{tabular}

Table 2: Thickness V/S \% of elongation and Flexural strength of $10 \%$ reinforcement of coir

\begin{tabular}{|l|l|l|l|}
\hline $\begin{array}{l}\text { Percentage of } \\
\text { coir } \\
\text { reinforcement }\end{array}$ & $\begin{array}{l}\text { Thickness } \\
\text { in } \mathrm{mm}\end{array}$ & $\begin{array}{l}\text { Percentage } \\
\text { of } \\
\text { elongation }\end{array}$ & $\begin{array}{l}\text { Flexural } \\
\text { strength } \\
\text { in MPa }\end{array}$ \\
\hline \multirow{4}{*}{10} & 3 & 6.3 & 52 \\
\cline { 2 - 4 } & 3.5 & 6.8 & 55 \\
\cline { 2 - 4 } & 4 & 7.3 & 63 \\
\cline { 2 - 4 } & 4.5 & 6.4 & 61 \\
\cline { 2 - 4 } & 5 & 5.8 & 60 \\
\hline
\end{tabular}

Table 3: Thickness V/S \% of elongation and Flexural strength of $15 \%$ reinforcement of coir

\begin{tabular}{|l|l|l|l|}
\hline $\begin{array}{l}\text { Percentage of } \\
\text { coir } \\
\text { reinforcement }\end{array}$ & $\begin{array}{l}\text { Thickness } \\
\text { in mm }\end{array}$ & $\begin{array}{l}\text { Percentage } \\
\text { of } \\
\text { elongation }\end{array}$ & $\begin{array}{l}\text { Flexural } \\
\text { strength in } \\
\text { MPa }\end{array}$ \\
\hline \multirow{4}{*}{15} & 3 & 6.6 & 54 \\
\cline { 2 - 4 } & 3.5 & 6.7 & 57 \\
\cline { 2 - 4 } & 4 & 7.0 & 65 \\
\cline { 2 - 4 } & 4.5 & 6.4 & 64 \\
\cline { 2 - 4 } & 5 & 6.1 & 62 \\
\hline
\end{tabular}

Table4: Thickness V/S \% of elongation and Flexural strength of $20 \%$ reinforcement of coir

\begin{tabular}{|l|l|l|l|}
\hline $\begin{array}{l}\text { Percentage of } \\
\text { coir } \\
\text { reinforcement }\end{array}$ & $\begin{array}{l}\text { Thickness } \\
\text { in mm }\end{array}$ & $\begin{array}{l}\text { Percentage } \\
\text { of } \\
\text { elongation }\end{array}$ & $\begin{array}{l}\text { Flexural } \\
\text { strength } \\
\text { in MPa }\end{array}$ \\
\hline \multirow{3}{*}{20} & 3 & 6.7 & 58 \\
\cline { 2 - 4 } & 3.5 & 7.1 & 61 \\
\cline { 2 - 4 } & 4 & 7.4 & 69 \\
\cline { 2 - 4 } & 4.5 & 6.3 & 67 \\
\cline { 2 - 4 } & 5 & 6.0 & 66 \\
\hline
\end{tabular}

Table 5: Thickness V/S \% of elongation and Flexural strength of $25 \%$ reinforcement of coir

\begin{tabular}{|l|l|l|l|}
\hline $\begin{array}{l}\text { Percentage of } \\
\text { coir } \\
\text { reinforcement }\end{array}$ & $\begin{array}{l}\text { Thickness } \\
\text { in mm }\end{array}$ & $\begin{array}{l}\text { Percentage } \\
\text { of } \\
\text { elongation }\end{array}$ & $\begin{array}{l}\text { Flexural } \\
\text { strength in } \\
\text { MPa }\end{array}$ \\
\hline \multirow{3}{*}{25} & 3 & 6.2 & 48 \\
\cline { 2 - 4 } & 3.5 & 6.5 & 56 \\
\cline { 2 - 4 } & 4 & 6.7 & 63 \\
\cline { 2 - 4 } & 4.5 & 6.1 & 60 \\
\cline { 2 - 4 } & 5 & 5.9 & 59 \\
\hline
\end{tabular}

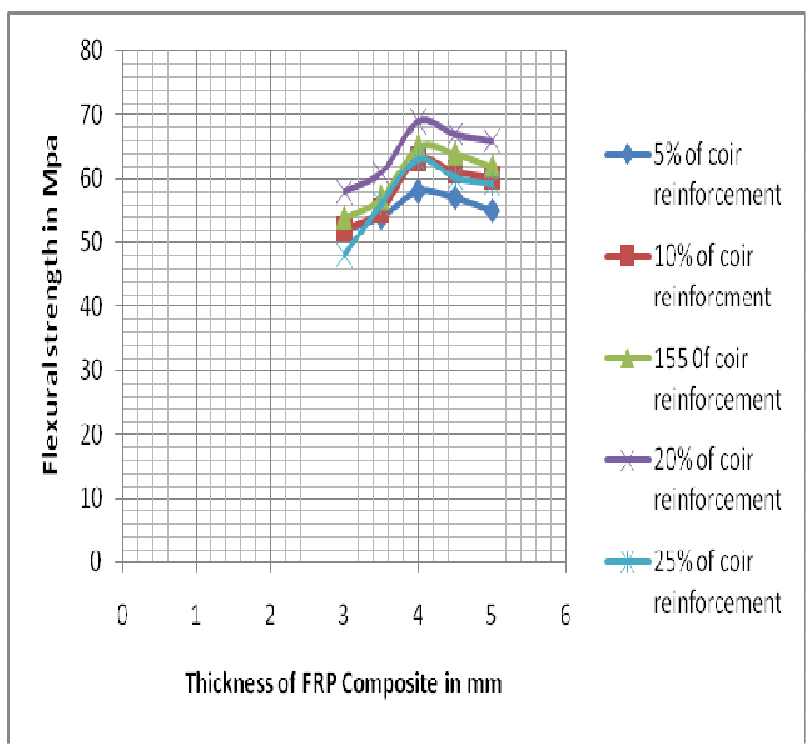

Fig-5: Flexural strength V/S Thickness of FRP Composite

From the observation of the Fig 5 clearly indicating the $20 \%$ of coir reinforcement exhibited higher value flexural strength at all thickness level of 3,3.5 4, 4.5 and $5 \mathrm{~mm}$ composites. It was exhibited higher value due to effective bonding strength between coir and polymer matrix, gas porosity formation is very negligible and also appearance and surface finish are very good compared to all other reinforcement. In the 5\% of reinforcement flexural strength increases gradually with increases in fiber percentage up to20 percentage of coir 
reinforcement and then decreases suddenly but in the $10,15 \%$ of reinforcement flexural strength increases suddenly with increases in fiber percentage up to20 percentage of coir reinforcement and then decreasessgradually $25 \%$ reinforcement exhibited poor flexural strength at all level of thickness. From the data of tested results conclude that $20 \%$ of coir reinforcement at $4 \mathrm{~mm}$ thickness of polymer composite exhibited higher flexural strength.

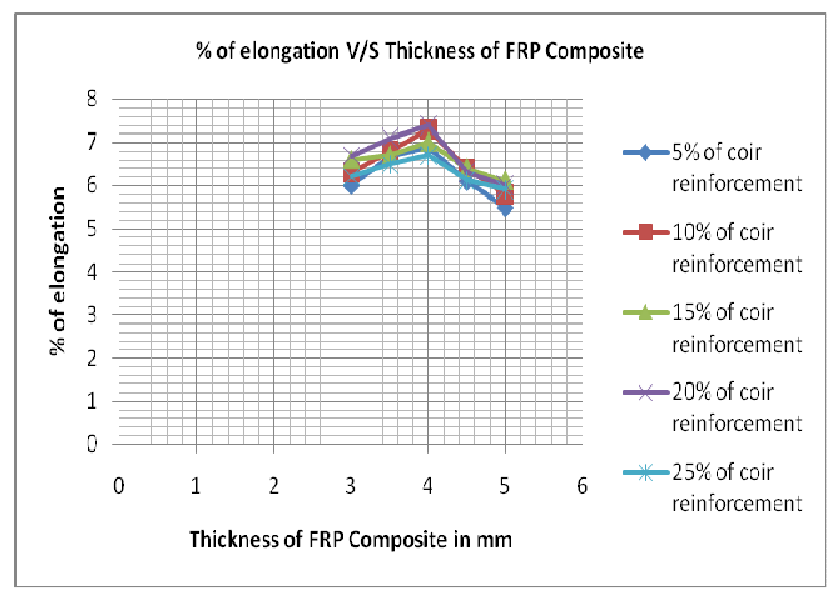

Fig-6: \% of elongation V/S Thickness of FRP Composite

From the observation of the Fig 6 clearly indicating the 20\% of coir reinforcement exhibited higher percentage of elongation at $4 \mathrm{~mm}$ thickness of composites. It was exhibited higher value due to effective bonding strength between coir and polymer matrix .percentage of elongation increases gradually with increases in fiber percentage up to20 percentage of coir reinforcement and then decreases suddenly but in the $10,15 \%$ of reinforcement, percentage of elongation increases suddenly with increases in fiber percentage up to20 percentage of coir reinforcement and then decreasessgradually $25 \%$ reinforcement exhibited poor percentage of elongation at all level of thickness. From the data of tested results conclude that $20 \%$ of coir reinforcement at $4 \mathrm{~mm}$ thickness of polymer composite exhibited higher percentage of elongation

\section{CONCLUSIONS}

The values obtained from the above graphs and result shows that fiber content plays a major role in determining mechanical properties of Natural fiber reinforced polymer resin composite. In natural fiber (coir) reinforced polymer matrix (vinyl ester). It is recommend to use Coir at an moderate ratio and the air bubbles in the laminate should be avoided and the fiber distribution has to be uniform throughout the laminate to get better strength. The $20 \%$ of coir reinforcement exhibited higher value flexural strength at 4 mmthickness of composite. It was exhibited higher value due to effective bonding strength between coir and polymer matrix, gas porosity formation is very negligible and also appearance and surface finish are very good compared to all other reinforcement.

\section{ACKNOWLEDGEMENTS}

I wish to thank to our HOD, Dr. N G Subramanya Udupa, Department of Mechanical Engineering (PG) at Nagarjuna college Of Engineering \& Technology, Bangalore, for guiding and encouraging me throughout the work

\section{REFERENCES}

[1] Mohanty, A K : M, Drazl. LT: Sustainable biocomposites from renewable resources ; opportunites and challenges in the green materials world, " Journals Of Polymers and The Envirnoment', vol 10, no.1-2, 2002 19-26.

[2] Biagiotti, J ; Fiori, s ; Torre. L; Lopez- Manchado, MA; Kenny, JM; Mechanical properties of polypropylene matrix composites reinforced with natural fibers : A statical approach.' Polymer Composites', vol. 25, no1, 2004, 26-36.

[3] Nabi Saheb. D; Jog JP: Natural fiber polymer composites : A Review' adv. Polymer tech.', vol 18 no. 4, 1999, 351-363.

[4] Karina, Myrtha; Onggo, Holia; Syampurwadi, Anung; Physical and mechanical properties of natural fibers filled polypropylene composites and its recycle,' Journal of Biological Sciences', vol. 7, no 2, 2007, 393-396.

[5] Esfandiari, Amirhossein; Mechanical properties of PP/jute and glass fibers composites: The statistical investigations ,'journal of Applied Sciences', vol 7 no. 24, 2007.3943-3950.

[6] Tajvidi, Mehdi ; Falk, Robert H; Hermanson, Jhon C :Effect of natural fibers on thermal and mechanical properties of natural fiber polypropylene composites studied by dynamic mechanical analysis, Journal of Applied polymer Sciences', vol.101 2006 , 4341-4349.

[7] Xiaoya Chen, Qipeng Guo, Yongli Mi : Bamboo fiber reinforced polypropylene composites : A study of the Mechanical Properties, 'journal of Applied Polymer Sciences, vol. 69, 1998, 1891-1899.

[8] Mohanty, Smita; Verma, Sushil K; Nayak, Sanjay K ; Tripathy Sudhansu S: Influence of Fiber treatment on the Performance of Sisal Polypropylene Composites, 'journal of Applied Polymer sciences ', vol. 94, 13361345.

[9] Joseph, PV Joseph Kuruvilla; Thomas, Sabu: effect of processing variables on the mechanical properties of sisal fiber reinforced polypropylene composites, 'composites science and technology', vol. 59, 1999, 1625-1640. 


\section{BIOGRAPHIE}

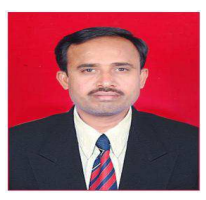

Dr. Rajanna.S, MIE, has proven track records of valuable services in teaching and research for 18 years at various Institutions which are affiliated to Bangalore University and VTU University. Successfully operated funded research projects, guided BE and M.Tech students published 11 Technical papers in National and International Journals. Presented 26 Technical papers in National and International Conferences and attended 15 workshops, seminars and staff development programmes in various Institutions and have been a member of 05 Professional bodies like IIW, IEI etc. 